\title{
Construint la visió sistèmica del cos humà a par- tir de la lectura crítica d’una controvèrsia socio- científica
}

\author{
Ana Ma Domènech (anamaria.domenech@uab.cat) \\ Conxita Márquez (conxita.marquez@uab.cat) \\ Grup LIEC i Dept de Didàctica de les Matemàtiques i les Ciències Experimentals, UAB
}

En aquest article es mostra el desenvolupament d'una activitat, realitzada a $3 r$ d'ESO $i$ 1r de batxillerat per treballar la visió sistèmica del cos humà a través de la lectura crítica de la entrevista d'un farmacèutic publicada a un diari. L'activitat vol promoure el desenvolupament d'aquest coneixement científic i la capacitat per analitzar una controvèrsia sociocientífica de manera fonamentada.

Paraules clau: controvèrsies sociocientífiques, lectura crítica, visió sistèmica cos humà

\section{INTRODUCCIÓ}

Actualment, al currículum vigent al nostre país (Decret 143/2007 DOGC núm.4915) i al marc teòric del projecte PISA (OCDE, 2007), es defineix que la finalitat de l'educació és promoure que els alumnes adquireixin les eines necessàries per entendre el món en el que estan creixent $i$ que aquestes puguin guiar les seves actuacions com a ciutadans capaços d'intervenir d'una manera activa i crítica en la societat que els ha tocat viure, caracteritzada per ser plural, diversa i en continu canvi.

Si ens fixem en la ciència amb la que es troben els ciutadans, ens adonem que és ben diferent a la que es sol treballar a la classe de ciències. Mentre que temes en els que la ciència i la societat estan lligades (com l'ús de les cèl·lules mare, la selecció genètica, l'estudi de l'ús dels efectes de la telefonia mòbil, la construcció d'un cementiri nuclear...) apareixen amb elevada freqüència als mitjans de comunicació, a les classes de ciències, s'ensenya, o la majoria dels alumnes acaben tenint una percepció de la ciència, com un conjunt de teories inqüestionables que expliquen fenòmens, però, poques vegades es parla de les preguntes a les que donen resposta i del procés de diàleg mitjançant el qual s'ha arribat a aquest coneixement i al consens existent entorn d'aquest (Kolsto, 2001).
En aquest context, des de la didàctica de les ciències es proposa la incorporació de les controvèrsies sociocientífiques a les classes de ciències, entenent, que es tracta de dilemes socials en els que la ciència està implicada fruit de la complexa interrelació existent entre elles (España i Prieto, 2009). Aquests temes es caracteritzen per ser oberts, complexes i controvertits com a resultat de la manca de consens científic i d'una resposta única i definitiva davant el problema (ja que són situacions noves que es situen en l'anomenada ciència frontera) (Ekborg i altres, 2009).

Totes aquestes característiques fan que es considerin un bon context per treballar aspectes relacionats amb: la naturalesa de la ciència (què és i com es fa la ciència, el paper del diàleg i el consens,...), l'argumentació i la competència d'ús i reconeixement de proves, la transferència i aplicació de coneixements científics en preses de decisions (Sadler i Dawson, 2012).

Seguint totes aquestes consideracions, s'ha dissenyat una unitat didàctica en la que es pretén treballar la controvèrsia associada a la medicalització de la societat i al cas concret del Trastorn per Dèficit d'Atenció amb o sense Hiperactivitat (TDA$H$ ) relacionant-les amb el treball dels continguts $i$ objectius del bloc del cos humà a $3 r$ d'ESO o l'apartat "ciència, salut i estils de vida" de 
l'assignatura de Ciències per al Món Contemporani al batxillerat. En aquest article es mostra la primera de les dues seqüències d'activitats de la unitat.

En aquesta primera seqüència es presenta la medicalització de la societat com a controvèrsia sociocientífica i s'emfatitza la relació sempre existent entre medicament i efectes secundaris a partir de la lectura crítica d'una entrevista de Contra de La Vanguardia. Després de treballar els coneixements científics implícits en aquesta relació mitjançant el cas concret de l'aspirina, es realitza un exercici de justificació d'accions respecte la medicació en diverses situacions de la vida quotidiana. Abans d'explicar les activitats dissenyades i dutes a termes, definirem què entenem nosaltres per medicalització de la societat i perquè creiem que és important treballar aquesta controvèrsia amb l'alumnat.

\section{La medicalització de la societat}

Fa mig segle a la llar no hi mancava un termòmetre de mercuri, fa més d'una dècada que hi ha termòmetres digitals, medidors de glucèmia i tot tipus d'estris relacionats amb la cura del cos. Fa vint anys, en una recerca sobre dos centenars de farmacioles domèstiques de classe mitja a Tarragona, es van trobar una mitjana de més de 100 medicaments a cada llar i es constatava que, en molts casos, el medicament havia substituït les mesures higienico-dietètiques i els remeis domèstics.

Avui en dia, alguns professionals defensen que estem assistint a una nova forma de medicalització de la vida que consisteix a crear malalties 0 ampliar els límits del que les defineix per incrementar la venda de medicaments i serveis de salut. Equiparar processos de la vida quotidiana, molèsties lleus i factors de risc a malaltia, expandeix el mercat de l'empresa farmacèutico-sanitària. És necessari prendre consciència del problema que això suposa per a la salut i tenir en compte que, malgrat sovint es tracta de manera implícita, els medicaments no es poden aïllar dels efectes secundaris que ens poden causar. Davant d'una possible medicació, les persones hem d'informar-nos i ser capaços de valorar el binomi risc-benefici abans de prendre una decisió.

\section{CARACTERÍSTIQUES DE LA SEQÜÈN- CIA DISSENYADA}

La seqüència es va plantejar com una aplicació dels continguts treballats sobre el cos humà. Es pretén treballar el model ésser viu, i, concretament, la relació sistèmica entre diverses funcions com la relació (a través sistema nerviós) i la nutrició. Tradicionalment, els sistemes del nostre cos s'estudien de manera aïllada i basant-se fonamentalment en la descripció de les estructures que formen part de cadascun d'aquests sistemes.

El fet de parlar dels medicaments $i$ dels seus efectes secundaris ens permet pensar en aquesta idea d'interrelació entre sistemes (si pensem en el recorregut del medicament des que l'ingerim fins que desenvolupa la seva acció) $i$ fomenta una visió més global de l'organisme (això explica que un medicament pugui actuar en diverses estructures del nostre cos i causar diferents efectes desitjats o no).

Els objectius proposats pretenien desenvolupar la capacitat de l'alumnat pel que fa a:

1) Aplicar tècniques de lectura crítica.

2) Definir la medicalització de la societat $i$ reconèixer-la com a una controvèrsia sociocientífica on hi ha implicats agents amb interessos diversos.

3) Explicar que els medicaments poden tenir efectes secundaris emfatitzant 0 aplicant la idea que el nostre cos actua com un sistema.

4) Utilitzar el coneixement científic per argumentar de manera fonamentada actuacions com a ciutadans responsables, especialment en relació amb la salut pròpia i la comunitària.

Aquesta seqüència d'activitats va ser aplicada durant els cursos 2010-2011 i 2011-2012 a grups d'alumnes de $3 r$ d'ESO i $1 r$ de batxillerat de diversos instituts del Vallès Occidental i Barcelona.

\section{a) Punt de partida: l'activitat d'idees prèvies}

Per iniciar l'activitat es va demanar a l'alumnat que llegís el títol de la entrevista i que individualment contestés les següents preguntes:

- El títol de la Contra és una frase dita pel JoanRamon Laporte: "Ios medicamentos pueden curar o causar cualquier enferdad". Tenint això en compte, creus que els medicaments poden curar o qualsevol malaltia? Justifica la teva resposta. 
- Una altra frase destacada de la entrevista és: "la diferència entre un medicament i un verí radica en la dosis". Què et suggereix aquesta afirmació?

- Quina informació trobaràs i de què creus que parlarà en Joan-Ramon Laporte en aquesta entrevista?

Quadre 1: Preguntes de l'activitat d'idees prèvies. Formen part de la primera fase de la lectura crítica.

Després, se'ls va demanar que conversessin en gran grup per intercanviar punts de vista i expressar els diferents arguments inicials. Les finalitats d'aquesta primera part van ser, d'una banda, motivar la lectura del text i introduir la medicalització de la societat i, per una altra, conèixer les idees prèvies de l'alumnat sobre els efectes secundaris dels medicaments i detectar si a partir de llegir el títol i una frase del text, l'alumnat és capaç de preveure el tipus d'informació que es trobarà a la entrevista.

\section{b) Lectura de l'entrevista}

Tot seguit, es va llegir la Contra (disponible a: http://grupsderecerca.uab.cat/liec/content/lasmedicinas-curan-o-causan-cualquier-enfermedad), de manera col-lectiva. Per fer-ho, es van seguir diferents estratègies, com per exemple: a) s'establia un diàleg entre el/la professor/a i els alumnes, el professor/a llegia les preguntes i després cada alumne llegia un paràgraf diferent, b) dos alumnes representaven la entrevista, un assumint el rol de l'entrevistador i l'altre el de l'entrevistat.

Una vegada s'havia llegit la Contra, els alumnes, per tal de seguir amb la tasca de lectura crítica, havien de contestar preguntes relacionades amb l'autor i el contingut. Respecte l'autor, és important tenir en compte que a la Contra s'havia omès la informació sobre la seva formació per explorar qui s'imaginaven els alumnes que podria dir tot això i veure si els sorprenia que un farmacèutic opinés d'aquesta manera, començant així a introduir la controvèrsia dins la ciència. Per tant, era important preguntar quina formació i professió creien que tenia la persona entrevistada i si els va sorprendre que fos un farmacèutic el que expressés aquestes idees.

Pel que fa al contingut, es proposava un treball per parelles 0 grups de 3 alumnes per tal d'identificar els punts de vista de l'entrevistat i amb quines proves els justifica. Els alumnes havien d'escriure quin era el punt de vista de l'autor res- pecte els 3 temes que es comentaven a l'entrevista (efectes secundaris, medicalització, indústria farmacèutica). Mentre s'identificaven els punts de vista, havien d'assenyalar en el text amb quines proves els fonamenta l'entrevistat. Per fer-ho, es va proporcionar als alumnes una còpia de la Contra en Din-A3 i marcadors de diferents colors perquè marquessin les proves amb les que creien que l'autor fonamentava els seus punts de vista amb marcadors de diferents colors.

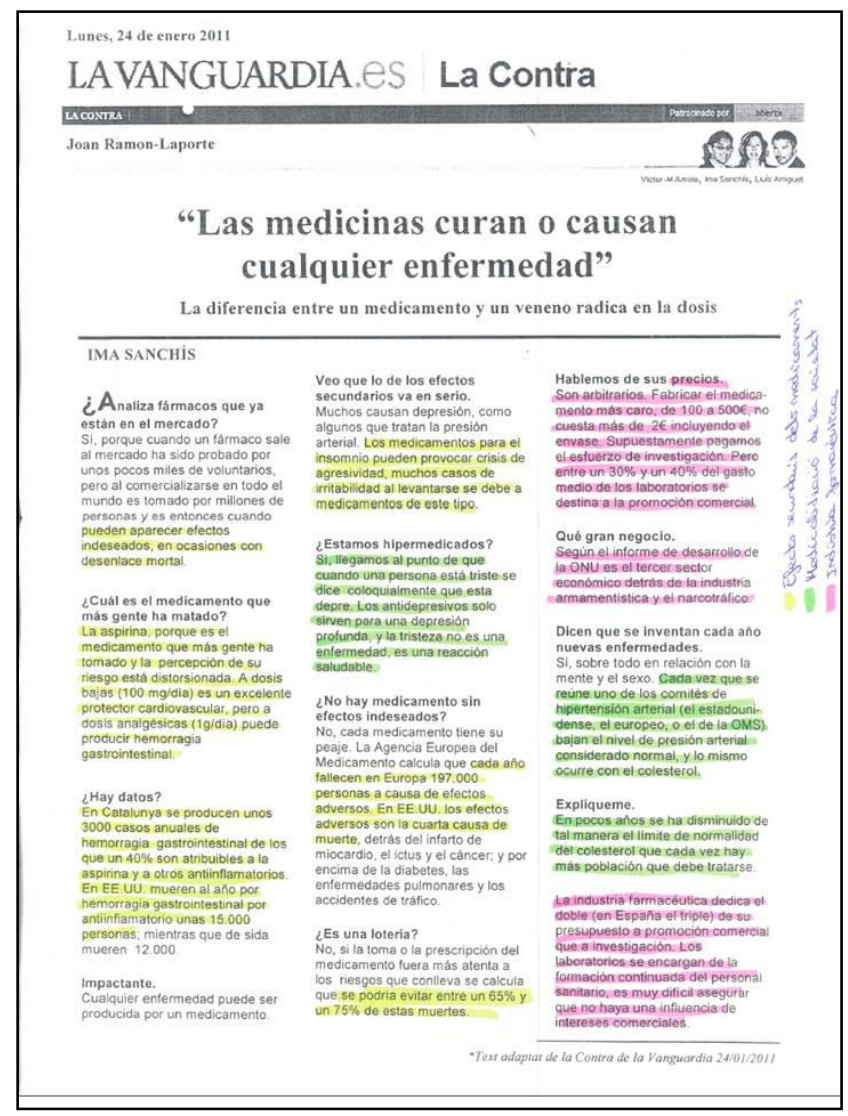

Figura 1: Exemple d'una de les Contres analitzades per un grup de $1 r$ de Batxillerat. En groc estan senyalades les proves amb les que l'autor fonamenta el seu punt de vista sobre els efectes secundaris dels medicaments, en verd els de la medicalització de la societat i en rosa els referents a la indústria farmacèutica.

Després d'aquesta anàlisi, es va fer una discussió grupal en la que l'alumnat explicava quines proves havien identificat per cadascun dels punts de vista mentre es comentava i reflexionava sobre què consideraven que era un prova i quins criteris seguien per tal de poder-les identificar i distingir d'altres dades com opinions personals de l'entrevistat. 
Per finalitzar aquest apartat, es preguntava a l'alumnat què és el que els havia sorprès més de l'entrevista, a quins agents convocarien a una reunió per tal de posar fre als fets explicats pel JoanRamon Laporte i se'ls demanava que proposessin mesures tot especificant quin seria l'agent encarregat de dur-les a terme. D'aquesta manera, es pretenia explorar si l'alumnat era capaç d'identificar diversos agents i mirar-se la controvèrsia des de diferents perspectives.

\section{c) De l’aspirina al cos com a sistema}

Després de recordar que a la Contra es deia que l'aspirina era el medicament que més morts havia causat (perquè també era dels que més s'havia utilitzat), es preguntava als alumnes si alguna vegada havien pres una aspirina, en quines situacions ho havien fet, si s'havien fixat en el prospecte d'algun medicament i, en cas afirmatiu, si l'havien entès. A partir d'aquesta exploració d'idees prèvies, es mostrava el prospecte de l'aspirina, centrant-nos en la informació referent als efectes secundaris. Després de comentar els apartats típics d'un prospecte i destacar, d'una banda, la dificultat per comprendre el lèxic que s'utilitza, i per l'altra, el fet que pot causar-nos trastorns i problemes a moltes parts del cos i sistemes diferents, l'alumnat llegia aquest relat i responia a la següent pregunta:

\footnotetext{
Com veiem al prospecte, podem prendre l'aspirina en diverses situacions (si ens fa mal el cap, els músculs, tenim febre...) però això ens pot produir trastorns o d'altres efectes a diverses parts del nostre $\cos$. A continuació trobaràs un relat que ha fet el teu company sobre què creu que passa al nostre cos quan ens prenem una aspirina i quins dubtes té:

Ahir després de jugar a futbol em feia mal el genoll i vaig decidir prendre'm una aspirina $i$ una estona després vaig notar que el genoll ja no em feia mal. Suposo que quan me la vaig prendre, l'aspirina va arribar a la sang i va anar al genoll, curant-me el mal que tenia. Però, com sap l'aspirina on ha d'anar a actuar? A més, com que la puc prendre en moltes situacions diferents, com sap cada vegada on ha d'arribar i què ha de fer? També penso que el sistema nerviós deu donar ordres perquè ja no em faci mal, però no ho tinc del tot clar. A més, un altre dubte és, com pot ser que un medicament que en teoria m'ha de curar una cosa, em pugui causar altres danys?..
}

El teu company ha escrit "Suposo que quan me la vaig prendre, l'aspirina va arribar a la sang $i$ va anar al genoll, curant-me el mal que tenia". Tenint en compte el que has estudiat fins ara sobre el cos humà, com explicaries tu aquest procés? Per fer-ho pots considerar els següents aspectes: on creus que actua l'aspirina, com creus que actua, com hi amiba, quins sistemes del cos estan implicats,...)

Figura 2. Relat i activitat utilitzada per explorar les idees prèvies de l'alumnat sobre l'acció de l'aspirina al nostre cos i la possibilitat que ens causi efectes secundaris.
Els/les alumnes posaven en comú les seves explicacions i a partir de les seves intervencions es conduïa una discussió per tal d'introduir l'explicació científica. En aquest punt era important tenir en compte què havien treballat els alumnes respecte el sistema nerviós i com ho havien fet ja que proposàvem començar amb una breu explicació sobre el dolor i després passar a l'acció de l'aspirina. Per tal de sintetitzar el coneixement construït col-lectivament, els alumnes havien de contestar individualment a aquestes preguntes:

- Un company afirma que l'aspirina pot tenir efectes secundaris a tot el cos perquè quan te la prens, passa del sistema digestiu a la sang i, com que aquesta circula per tot el cos, pot arribar i interaccionar amb qualsevol part. Indica si aquesta afirmació és certa o no i justifica la teva resposta.

- A partir d'aquests conceptes (medicalització de la societat, efecte secundari, cos humà com a sistema, medicament) fes un petit text que expressi les idees principals que hem treballat aquests dies.

Quadre 2. Preguntes de l'activitat de síntesi.

Per fer-ho, podien consultar aquest dibuix informatiu sobre l'acció de l'aspirina:

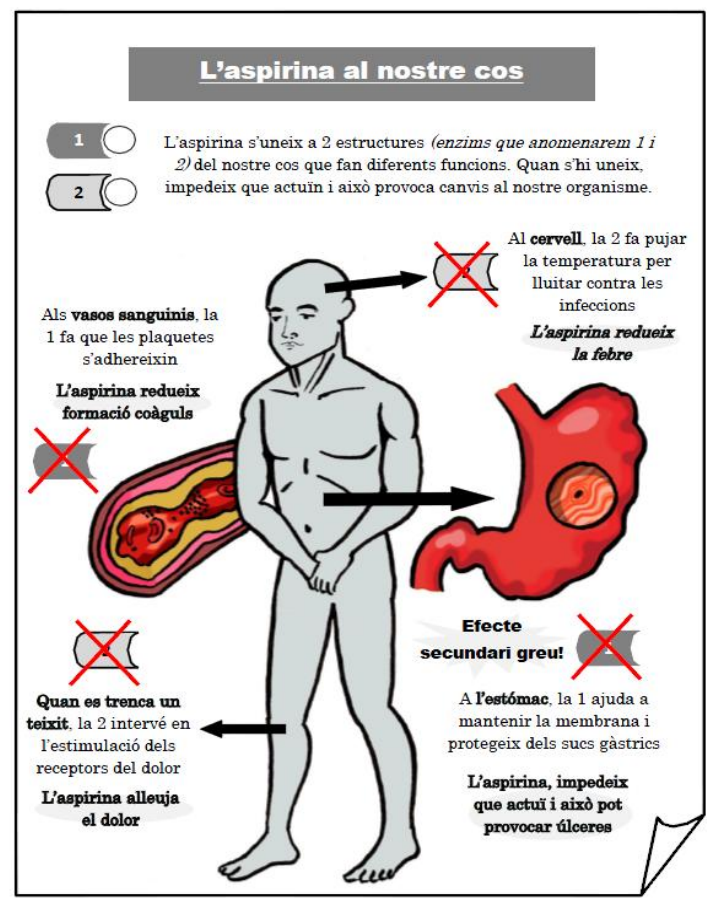

Figura 3. Esquema explicatiu de l'acció i dels possibles efectes secundaris de l'aspirina al nostre cos. 


\section{d) De la classe a les situacions quo- tidianes}

Per finalitzar aquesta seqüència, vam plantejar als alumnes 3 situacions quotidianes en les que es podia recórrer a la medicació (disponible a: http://grupsderecerca.uab.cat/liec/justificacio\%20m edicacio). L'alumnat havia de justificar què faria i quin era el seu punt de vista respecte la medicació en cadascuna de les situacions.

\section{RESULTATS}

Com comentarem a continuació, l'experiència presentada ha contribuït a que l'alumnat assolís els objectius que ens havíem plantejat i aporta informació que pot ser útil en el moment de dissenyar i implementar activitats amb temàtiques semblants a la tractada. Tot seguit comentarem aquells aspectes que trobem més rellevants.

Fixant-nos en les respostes que els/les alumnes van donar en l'activitat prèvia a la lectura de la Contra, ens adonem que hi ha una sèrie d'idees prèvies respecte els efectes secundaris que són recurrents i que després influeixen en com l'alumnat explica l'acció de l'aspirina. Per tant, és important tenir-les en compte quan es plantegin activitats relacionades amb els medicaments i el seu ús. Les idees mencionades pels alumnes són: a) els efectes secundaris són propis dels medicaments, tots en tenen, actuen igual en totes les persones, és conseqüència de la seva naturalesa química; b) els medicaments només causen efectes secundaris si els consumim en una dosi superior a la recomanada pel metge; c) depèn de l'ús que en facis, és a dir, si et prens un medicament per una malaltia que no tenies, si t'automediques i prens medicaments per a tot,...; d) el sistema immunitari és el que fa que la diferència entre un medicament i un verí sigui la dosi (hi ha confusió amb el tema de les vacunes). Com hem pogut veure, la majoria de l'alumnat no pensa que un medicament recomanat pel metge i pres seguint les indicacions ens pugui causar efectes secundaris. Aquesta idea s'hauria de treballar per tal de facilitar la visió sistèmica del nostre cos.

Seguint amb les activitats de lectura crítica, ens agradaria remarcar que el fet de fer pensar als alumnes quin tipus d'informació creuen que es trobaran i, un cop llegit el text, fer preguntes sobre l'autor i el contingut, els ajuda a comprendre millor el text i poder aprofundir-hi; coincidint amb els resultats descrits per Oliveras i d'altres (2011). Respecte la identificació dels punts de vista manifestats per l'entrevistat i les proves amb les que els fomenta, hem detectat que la majoria de l'alumnat no té dificultats per identificar els punts de vista però sí per identificar les proves. És per aquest motiu que considerem que en el moment de realitzar aquesta activitat, al principi o un cop els alumnes hagin començat aquest exercici, s'hauria d'aclarir què són les proves i quins criteris es poden utilitzar per discriminar-les d'altres dades.

En referència a la construcció de la visió sistèmica del cos humà cal destacar que, les respostes de l'alumnat abans i després de la discussió col-lectiva foren força diferents. Al principi, quan els alumnes havien d'explicar com creien que actua l'aspirina al nostre cos, la majoria d'ells identificaven la intervenció de diferents sistemes, però, tenien dificultats per explicar bé la seva funció i, sobretot, relacionar-los. En canvi, a les respostes de les activitats de síntesi, els alumnes són capaços d'explicar aquesta relació a banda d'identificar la intervenció dels diversos sistemes i la seva funció. En aquest punt, però, apareix la dificultat de l'alumnat per entendre una altra idea clau en relació als efectes secundaris: la especificitat d'acció dels medicaments. No n'hi ha prou amb que, sigui quina sigui la via d'administració, els medicaments arribin a la sang i es distribueixin per tot el cos, s'ha de tenir en compte que només podran actuar allà on hi hagi les estructures específiques a les que s'uneix (enzims).

Ens agradaria destacar que, analitzant les respostes dels diversos grups d'alumnes participants, hem pogut constatar que, en aquells grups on el professor ha comentat de manera col-lectiva el dibuix de la figura 3 , quan els alumnes contesten la primera pregunta de l'activitat de síntesi, fan més referència a aquesta idea d'especificitat que els altres.

Finalment, respecte l'anàlisi de la medicalització de la societat com a controvèrsia, podem dir que els alumnes han estat capaços de veure la controvèrsia des de diferents angles ja que la majoria d'ells han identificat a tots els agents que hi estan implicats (els professionals de salut i les seves institucions, indústria farmacèutica i de materials mèdics, l'administració i gestors de serveis sanitaris, mitjans de comunicació i la població) i s'han proposat mesures per actuar davant les problemàtiques descrites.

Respecte la última activitat, dir que els alumnes quan justifiquen si es medicarien o no en diferents situacions quotidianes, fan referència a coneixe- 
ments científics treballats però, sobretot, tenen en compte els seus hàbits, ideologia i creences de caire moral i valors personals.

\section{CONCLUSIONS}

L'experiència presentada ha ajudat a l'alumnat a assolir els objectius prèviament marcats tant pel que fa al coneixement científic com al treball d'anàlisi de controvèrsies sociocientífiques.

Com hem pogut veure a l'apartat anterior, la majoria dels alumnes han aconseguit construir una visió del cos humà més sistèmica del que tenien inicialment. Per fer-ho, ha estat important explorar primer les seves idees prèvies i després construir la explicació científica de manera col-lectiva. La gestió de l'activitat també ha estat important alhora de treballar amb l'alumnat la idea que els medicaments tenen una acció específica, és a dir, per poder actua necessiten unir-se a una determinada estructura (en funció del que havien treballat els alumnes ens quedàvem amb aquesta idea o introduíem el terme "enzim"). En aquest cas, hem vist que era clau que el professorat ajudés a l'alumnat a analitzar un esquema de l'acció de l'aspirina al nostre cos (figura 3 ) on es veia reflectida aquesta idea. Aquells grups on els/les alumnes han fet un treball més autònom, la referència a aquesta idea en les activitats de síntesi, ha estat menor.

Pel que fa a l'anàlisi de la medicalització de la societat com controvèrsia sociocientífica, hem detectat que aquesta seqüència d'activitats ha ajudat a l'alumnat a reconèixer la controvèrsia, identificar els diferents agents que hi estan implicats i proposar mesures per posar-hi fre. Cal destacar, però, que l'agent en relació al qual s'han proposat menys mesures és la població. D'aquesta manera es fa palès el fet que pels alumnes és més fàcil focalitzar la responsabilitat en altres agents que en ells mateixos. Per aquest motiu, pensem que seria interessant treballar aquest aspecte en activitats similars a la descrita en aquest article.

Considerem que el fet de: a) contextualitzar una idea complexa com és la visió sistèmica del cos humà en una controvèrsia sociocientífica significativa pels alumnes, b) treballar la lectura crítica d'un text que l'alumnat es podria trobar fora de les classes de ciències $i, c)$ connectar tot això amb els coneixements científics a través d'una experiència viscuda per l'alumnat (prendre una aspirina i llegir el prospecte d'aquest medicament); pot servir d'exemple com a estratègia per ajudar als alumnes a comprendre millor fenòmens de la vida quotidiana i treballar algunes competències bàsiques del currículum com la competència científica o la comunicativa lingüística.

Per tant, pensem que el treball de controvèrsies sociocientífiques a les classes de ciències pot ajudar a millorar la comprensió de coneixements científics que hi estiguin relacionats $i$ ajudar als alumnes a establir vincles entre el que es treballa a la classe i les experiències quotidianes.

Per últim, destacar que els/les alumnes han valorat aquesta experiència de manera molt positiva i han estat engrescats i motivats en totes les activitats dutes a terme.

\section{REFERÈNCIES}

EKBORG, Margareta, IDELAN, Malin. i MALMERG Claes (2009). "Science for life-a conceptual framework for construction and analysis of socio-scientific cases". Nordina, Vol. 5, pàgs. 3546.

ESPAÑA, Enrique i PRIETO, Teresa (2009). "Educar para la sostenibilidad: El contexto de los problemas sociocientíficos". Revista Eureka Sobre Enseñanza y Divulgación De Las Ciencias, Vol. $6, \mathrm{n}^{\circ} 3$, pàgs. $345-354$.

KOLSTO, Stein D. (2001). "Scientific literacy for citizenship: Tools for dealing with the science dimension of controversial socioscientific issues". Science Education, Vol. 85, ํㅜ, pàgs. 291-310

OECD (2007). OECD Programme for International Student Assessment (PISA). [article en línia]. OECD PISA [Data de consulta: 29 de desembre de 2012]

http://www.oecd.org/pisa/pisaproducts/pisa2006/

OLIVERAS, Begoña, MÁRQUEZ, Conxita. i SANMARTÍ, Neus (2011). "The use of newspaper articles a $s$ a tool to develop critical thinking in Science Classes". International Journal of Science Education, Vol. 24, n¹0, pàgs. 997-1020.

SADLER, Troy D. i DAWSON, Vaille. (2012). "Socio-scientific Issues in Science Education: Contexts for the promotion of key learning outcomes". En FRASER, Barry J.; TOBIN, Kenneth; MCROBBIE, Campbell J. (Eds.) Second International Handbook of Science Education. Springer, Dordrecht Heidelberg London New York, vol.2, pàgs. 799-810. 


\section{AGRAIMENTS}

Aquesta recerca ha estat realitzada en el marc del grup LIEC (Llenguatge i Ensenyament de les Ciències), grup de recerca consolidat (referència 2009SGR1543) per l'AGAUR (Agència de Gestió d'Ajuts Universitaris i de Recerca) i finançada per la Dirección General de Investigación, Ministero de
Educación y Ciencia (referències EDU-200913890-C02-02 i EDU-2012-38022-C02-02) .

Les autores agraeixen la col-laboració dels professors/es i alumnes participants. 